九州大学学術情報リポジトリ

Kyushu University Institutional Repository

Effect of the Application of Rye-Grass on the Contents of Individual Amino Acids and Amino Sugars Contained in the Organic Nitrogen in So il

Marumoto, Takuya

Laboratory of Soil Fertility and Plant Nutrition, Faculty of Agriculture, Kyushu University

Furukawa, Kensuke

Laboratory of Soil Fertility and Plant Nutrition, Faculty of Agriculture, Kyushu University

Yoshida, Takashi

Laboratory of Soil Fertility and Plant Nutrition, Faculty of Agriculture, Kyushu University

Kai, Hideaki

Laboratory of Soil Fertility and Plant Nutrition, Faculty of Agriculture, Kyushu University 他

https://doi.org/10.5109/22817

出版情報：九州大学大学院農学研究院紀要. 17 (1)，pp.37-47，1972-08. Kyushu University バージョン：

権利関係: 
Fac. Agr., Kyushu Univ., 17, 37-47 (1972)

\title{
Effect of the Application of Rye-Grass on the Contents of Individual Amino Acids and Amino Sugars Contained in the Organic Nitrogen in Soil
}

\author{
Takuya Marumoto, Kensuke Furukawa, Takashi Yoshida, \\ Hideaki Kai and Togoro Harada
}

Laboratory of Soil Fertility and Plant Nutrition, Faculty of

Agriculture, Kyushu University, Fukuoka

(Received December 5, 1971)

\begin{abstract}
Six months after adding ${ }^{14} \mathrm{C}$-labelled rye-grass to sand and soil, the contents of amino acids and amino sugars in the organic nitrogen were examined. In both sand and soil, about 75 per cent of the added rye-grass ${ }^{14} \mathrm{C}$ was mineralized as carbon dioxide and a part of the ${ }^{14} \mathrm{C}$ added was incorporated into the amino compounds. Analytical results showed that Gly and Ala in organic nitrogen in both sand and soil were distinctly high in content, Glu, Asp and Lys were next, and Val, Thr, Ser and Leu followed, and that the amino acid compositon was not similar to that of the added rye-grass and amino sugar compounds were recognized. These facts suggest that when a plant material is decomposed in soil, its composition of amino compounds is exchanged through the microbiological metabolism and approaches what is contained in the soil natively, and that amino sugar compounds are synthesizeds newly and accumulated in soil due to their resistance to decomposition.
\end{abstract}

\section{INTRODUCTION}

A large number of studies on amino acid and amino sugar in soil have been reported. Bremner (1950), Davidson et al. (1951) and Sowden and Parker (1953) analyzed the amino acid composition of acid hydrolysates of soil by paper chromatography. Bremner (1950) studied the amino acid composition of acid hydrolysates of a variety of soils by paper chromatography and detected the following twenty amino acids in every hydrolysate examined: Phe, Leu, Ileu, Val, Ala, Gly, Thr, Ser, Asp, Glu, Lys, Arg, His, Pro, Tyr, Hpr, $\alpha \varepsilon$-Diaminopimelic acid, $\beta$-Alanine, $\alpha$-Amino- $n$-butyric acid and $\gamma$-Amino-butyric acid. After that, Stevenson (1954, 1956a,1956b), Sowden (1955, 1966), Wang et al. (1967) and Hayashi and Harada (1969) isolated and determined individual amino acids and amino sugars of acid hydrolysates of soil by ion exchange chromatography. Yamashita and Akiya (1966) fractionated the soil organic matter into the fulvic acid-, humic acid- and humin-fractions, and determined individual amino acids in these three fractions. On the basis of the data reported by them, it is found that the amino acid composition in these three fractions is reciprocally very similar. 
According to the research reports mentioned above, it seems that the major amino acids in soil are Gly, Ala, Asp, Glu, Thr, Ser, Val, Lys and Leu. Furthermore, with regard to the percentages of individual amino acids which are calculated as Mol percentage of the total Mol of amino acid, it may safely be said that they show the following order as a trend: Gly, Ala, Glu, Asp, Thr, Ser> Val, Lys, Leu, etc.

The studies on the amino sugars in soil have been reported by Bremner and Shaw (1954), Stevenson (1957a, 1957b,1957c), Stevenson and Braids (1968) and Sowden (1959). According to their results, the amino sugar contents are about 10 per cent of the total organic nitrogen in soil, and the major parts of amino sugar are glucosamine and galactosamine.

Wagner and Mutatkar (1968) investigated about amino acid components of organic matter formed during humification of ${ }^{14} \mathrm{C}$-labelled glucose in soil. From its results, the higher radioactivity of ${ }^{14} \mathrm{C}$ was present in Ala, Gly, Glu, Glucosamine, Asp, Thr, Ser and Lys than in the other amino compounds. The reports of this type have hardly been published to date.

The purpose of this investigation is to obtain the reliable information on a tendency of the contents of individual amino acids and amino sugars contained in the organic nitrogen in soil through the application of rye-grass labelled with ${ }^{11} \mathrm{C}$ uniformly. The outline of the experiments is as follows: 6 months after adding ${ }^{11} \mathrm{C}$-labelled rye-grass as a plant material to sand and soil, the organic matter accumulated was hydrolyzed with acid and amino compounds were isolated by ion exchange chromatography.

\section{MATERIALS AND METHODS}

\section{Soil and sand}

The soil used in this experiments was sampled from the paddy field of the Agricultural Experiment Station of Toyama Prefecture. After sampling, the soil was sieved through a $2 \mathrm{~mm}$ screen without air-drying, put in a polyethylene bag and stored in a room at $4^{\circ} \mathrm{C}$. It contained $\mathbf{0 . 1 8}$ per cent nitrogen and 2.34 per cent carbon per dry soil. Its texture was sandy loam.

The sea sand (Yoneyama Chemical Company) was ground in a mortar and pestle to 32-60 mesh size. Then, it was washed with water and air-dried.

\section{${ }^{14} \mathrm{C}$-labelled rye-grass}

The rye-grass labelled with ${ }^{14} \mathrm{C}$ uniformly was air-dried, ground finely and used. The contents of carbon and nitrogen of the rye-grass are 35.0 per cent and $\mathbf{0 . 6}$ per cent, respectively, on the basis of the air-dry material. Its $\mathrm{C} / \mathrm{N}$ ratio is about 58 .

\section{Incubation procedures}

Ten $\mathrm{g}$ of moist soil was weighed into $50 \mathrm{ml}$ Erlenmeyer flask, and $400 \mathrm{mg}$ of ${ }^{11} \mathrm{C}$-labelled rye-grass was added to the soil. The sample was mixed throughly. Then, it was adjusted to bring the moisture content to $\mathbf{5 0}$ per cent of the maximum water holding capacity with distilled water, covered with poly- 
ethylene film and incubated at $30^{\circ} \mathrm{C}$ for the period of 6 months. As a control, only soil was incubated without rye-grass application in the same way as mentioned above. In addition $10 \mathrm{~g}$ of sea sand and $400 \mathrm{mg}$ of ${ }^{11} \mathrm{C}$-labelled rye-grass were weighed into $50 \mathrm{ml}$ flask, mixed throughly and then incubated in the same way as the soil. To correct water loss during the incubation as determined by weighing the flasks, distilled water was added to them at intervals.

\section{Determination of amino acids and amino sugars}

After B-month incubation of samples, the soil organic matter was hydrolyzed with $6 \mathrm{~N} \mathrm{HCl}$ at $105^{\circ} \mathrm{C}$ for 20 hours under reflux and amino acid compounds were isolated by ion exchange chromatography. Individual amino acids in the solution were determined by Moore's method (1951) employing the KLA 2 Type Hitachi Amino Acid Analyzer. For amino sugar determination, the samples were hydrolyzed with $6 \mathrm{~N} \mathrm{HCl}$ at $100^{\circ} \mathrm{C}$ for 6 hours under reflux. Amino sugars in the solution prepared was determined/by Elson and Morgan's method (1933) modified by Stevenson (1957c). The effluent positions of individual amino acids and amino sugars were confirmed by the use of standard preparations.

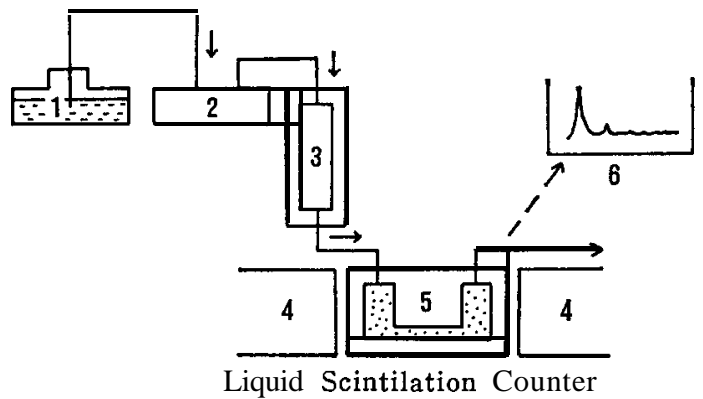

Fig. 1 Block diagram of labelled amino acid analyser.

1. Na-citrate buffer, 2. Micropump, 3. Amberite IR 120, 4. Photo-Tube, 5. FlowCell, 6. Flow-Chart.

${ }^{14} \mathrm{C}$ radioactivities of amino acid fraction and amino sugars were measured by using liquid scintilation counter (Kobe Industrial Company GSL 151 Type) with Flow-Cell as shown in Fig. 1. For the total counts of ${ }^{14} \mathrm{C}$ of samples, ${ }^{14} \mathrm{CO}_{2}$ evolved by wet combustion using Kosaka's method (1959) was absorbed into $10 \mathrm{~N} \mathrm{KOH}$ solution and then, its ${ }^{14} \mathrm{C}$ counts in the solution were measured by using liquid scintilation counter as mentioned above.

\section{RESULTS AND DISCUSSION}

\section{(1) ${ }^{14} \mathrm{C}$ activity of amino acid and amino sugar}

The counts of total labelled organic ${ }^{14} \mathrm{C}$ and amino compound ${ }^{14} \mathrm{C}$ of the (Initial rye-grass), the (Sand+rye-grass) after incubation and the <Soil+ryegass) after incubation were shown in Table 1 . In view of the total counts, $231.0 \times 10^{4} \mathrm{cpm}$ of the (Initial rye-grass) decreased to $56.7 \times 10^{4} \mathrm{cpm}$ of the (Sand +rye-grass $>$ and to $58.5 \times 10^{4} \mathrm{cpm}$ of the (Soilfrye-grass). These data dis- 
Table $1 .{ }^{14} \mathrm{C}$ counts in the <Initial rye-grass $\rangle$, the $\langle$ Sand + rye-grass $\rangle$ and the $<$ Soil+ rye-grass $>$.

\begin{tabular}{|c|c|c|c|}
\hline & $\begin{array}{l}\text { Total count } \\
\left(\times 10^{4} \mathrm{cpm}\right)\end{array}$ & $\begin{array}{c}\text { Amino } \\
\text { Compound } \\
\text { count }^{1)} \\
\left(\times 10^{4} \mathrm{cpm}\right)\end{array}$ & $\begin{array}{c}\text { Amino } \\
\text { Compound } \\
(\mu \mathrm{Mol})\end{array}$ \\
\hline Initial rye-grass ${ }^{3}$ & $\begin{array}{c}231.0 \\
(100.0)\end{array}$ & $\begin{array}{l}12.9 \\
(5.6)\end{array}$ & 121.0 \\
\hline Sand + rye-grass ${ }^{4}$ & $\begin{array}{c}56.7 \\
(100.0)\end{array}$ & $\begin{array}{c}12.5 \\
(22.0)\end{array}$ & 132.7 \\
\hline Soil +rye-grass ${ }^{53}$ & $\begin{array}{c}58.5 \\
(100.0)\end{array}$ & $\begin{array}{c}13.5 \\
(23.1)\end{array}$ & 500.0 \\
\hline
\end{tabular}

1) Including the amino acid- and the amino sugar-fractions. 2) See Tahle $2 . \quad 3$ ) Per $400 \mathrm{mg}$ rye-grass. 4) Per $10 \mathrm{~g}$ sand. 5) Per $10 \mathrm{~g}$ soil. Figures in parenthesis were calculated as per cent of total count.

tinctly indicate that 6 months after adding ${ }^{11} \mathrm{C}$-labelled rye-grass to sand and soil, about 75 per cent of the added rye-grass ${ }^{14} \mathrm{C}$ were mineralized and volatilized as carbon dioxide. The counts of amino compound ${ }^{14} \mathrm{C}$ in the (Initial rye-grass), the 〈Sand+rye-grass〉 and the (Soilfrye-grass) were $12.9 \times 10^{1} \mathrm{cpm}$, $12.5 \times 10^{\prime} \mathrm{cpm}$ and $13.5 \times 10^{1} \mathrm{cpm}$, respectively. And then, these data clearly show that part of ${ }^{11} \mathrm{C}$ added was incorporated into amino compounds in both sand and soil after 6-month incubation and the amounts of ${ }^{14} \mathrm{C}$ incorporated were hardly different between sand and soil.

Chromatograms of ${ }^{14} \mathrm{C}$ activities of amino acids and amino sugars in the IInitial rye-grass) and the (Sandfrye-grass) were shown in Fig. 2. As seen in Fig. 2, two peaks of ${ }^{14} \mathrm{C}$-labelled amino sugars were only detected in the (Sand

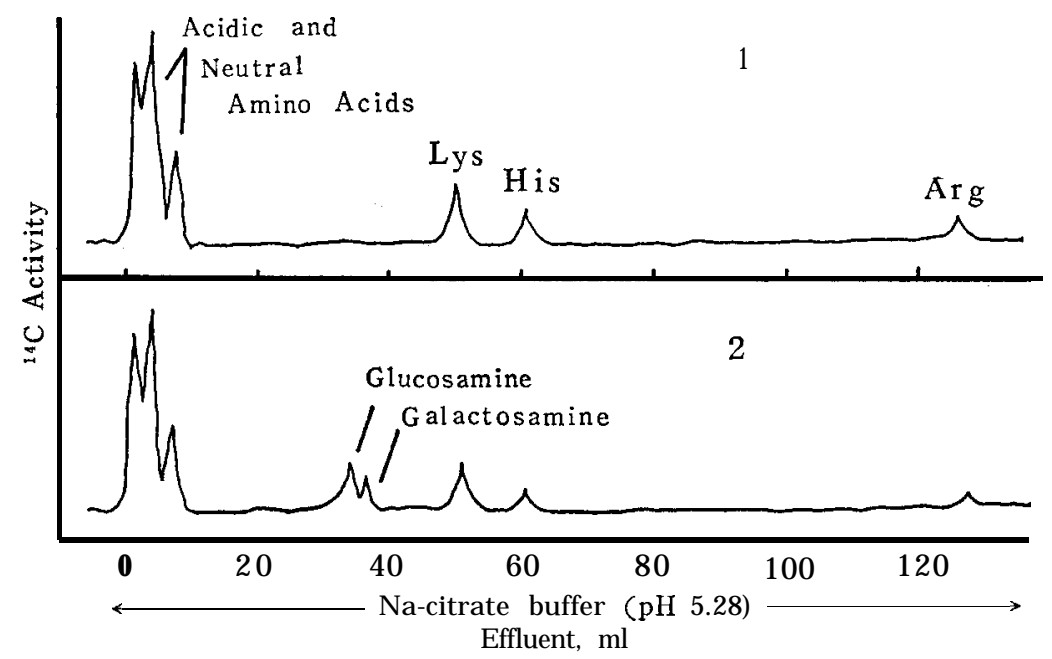

Fig. 2 Chromatograms of ${ }^{14} \mathrm{C}$ activities of amino acids and amino sugars in the $<$ Initial rye-grass $>$ and the <Sand+rye-grass).

1. <Initial rye-grass>, 2. <Sand+rye-grass>. 
+rye-grass $\rangle$. The former was glucosamine, the later was galactosamine. This clearly suggests that the amino sugars were synthesized by soil microorganisms through the process of decomposition of the added rye-grass. Though chromatogram of "C activities of amino compounds in the (Soilfrye-grass) was abbreviated, in the (Soil+rye-grass), also, the same peaks as the 〈Sand+ryegrass) were obtained and the amino sugars were synthesized undoubtedly.

Note : Though ${ }^{14} \mathrm{C}$ activities of individual amino acids and amino sugars in the amino compounds were determined by Flow-Cell, we could not obtain quantitative data about them. So, they were abbreviated. With regard to the contents of individual amino acids and amino sugars contained in the organic nitrogen in sand or soil, they were calculated from the data determined by Ninhydrin colorimetry (Moore et al., 1951) and Elson and Morgan's method (1933), respectively.

\section{(2) Contents of individual amino acids and amino sugar}

Contents of individual amino acids and amino sugar in the (Initial rye-grass), the (Sandfrye-grass), the (Soil+rye-grass), the (Control soil) and the (Initial soil) which were determined by Ninhydrin colorimetry and Elson and Morgan's method, respectively, were shown as Mol per $10 \mathrm{~g}$ of sand or soil in Table 2 . Besides, the Mol per cent of each amino acid of each treatment including the (Initial rye-grass) and the (Initial soil) which calculated as percentage of the total Mol of amino acid was also given in Table 2. Fig. 3 showed the percentage distribution of individual amino acids of each treatment including the (Initial rye-grass) and the (Initial soil).

In the first place, in view of the contents of amino acids and amino sugar,

Table 2. Amino acid compositions of the <Initial rye-grass>, the <Sand+rye-grass), the <Soil+rye-grass>, the <Initial soil > and the <Control soil $>$.

\begin{tabular}{|c|c|c|c|c|c|c|c|c|c|c|}
\hline \multirow[t]{2}{*}{$\begin{array}{l}\text { Amino } \\
\text { compounds }\end{array}$} & \multicolumn{2}{|c|}{$\begin{array}{c}\text { Initial rye-gsas } \\
\text { incubation } \\
\text { period } \\
0\end{array}$} & \multicolumn{2}{|c|}{$\begin{array}{c}\text { Sand }+ \text { rye-gsass } \\
\text { incubation } \\
\text { o e r i o d } \\
6 \text { \%months }\end{array}$} & \multicolumn{2}{|c|}{$\begin{array}{c}\text { Soilfrye-grass } \\
\text { incubation } \\
\text { oeriod } \\
6 \text { 'months }\end{array}$} & \multicolumn{2}{|c|}{$\begin{array}{l}\text { Initial soil } \\
\text { incubation } \\
\text { period } \\
0\end{array}$} & \multicolumn{2}{|c|}{$\begin{array}{c}\text { Control soil } \\
\text { incubation } \\
\text { period } \\
6 \text { months }\end{array}$} \\
\hline & ${ }^{\mu \mathrm{Mol}^{1)}}$ & $\%$ & $\mu \mathrm{Mol}^{2}$ & $\%$ & $\mu \mathrm{Mol}^{3)}$ & $\%$ & $\mu \mathrm{Mol}^{3)}$ & $\%$ & $\mu \mathrm{Mol}^{3}$ & $\%$ \\
\hline Lys & 2.9 & 6.4 & 6.8 & 5.7 & 38.9 & 9.6 & & 8.5 & 35.0 & 8.5 \\
\hline His & & 2.4 & 2.0 & 1.6 & 6.1 & 1.5 & 362.1 & 0. & 1.7 & 0.4 \\
\hline Arg & 3.4 & 2.8 & 1.6 & 1.3 & 4.1 & 1.0 & 43.84 .7 & 10.31.1 & 6.2 & 1.5 \\
\hline AsP & 9.2 & 7.7 & 11.8 & 9.8 & 21.1 & 5.2 & & & 42: 4 & 10.3 \\
\hline Thr & 6.1 & 4.6 & 8.2 & 6.8 & 17.8 & 4.4 & & 5.8 & 23.9 & 5.8 \\
\hline Ser & & 8.5 & 8.2 & 6.7 & 21.9 & 5.4 & 24.9 & 6.1 & 25.9 & 6.3 \\
\hline Glu & 16.6 & 13.9 & 15.8 & 13.1 & 26.7 & 6.6 & 37.4 & 8.8 & 38.7 & 9.4 \\
\hline Pro & & 8.9 & 5.6 & 4.6 & 32.4 & $8: 0$ & 17.8 & 4. & 17.3 & 4.2 \\
\hline Gly & 10.8 & 10.8 & 18.2 & 15.2 & 91.6 & 22.6 & 94.8 & 22 . & 86.8 & 21.1 \\
\hline Ala & 12.5 & 10.4 & 15.8 & 13.1 & 62.4 & 15.4 & 58.7 & 13.8 & 56.8 & 13: 8 \\
\hline Val & 6.4 & 5.3 & 8.2 & 6.7 & 25.9 & 6.4 & 25.5 & 6.0 & 23.5 & 5.7 \\
\hline Met & 0.8 & & 1.4 & 1.2 & 4.1 & 1.0 & 4.7 & 1.1 & 6.2 & 1.5 \\
\hline Ileu & 8.9 & 0.63 .6 & 4.4 & 3.6 & 15.4 & 3.8 & 11.9 & 2.8 & 12.7 & 3.1 \\
\hline Leu & 2.1 & 7.5 & 7.8 & 6.4 & 21.5 & 5.3 & 24: 2 & 5.7 & 22: 2 & 5.4 \\
\hline Tyr & 5.8 & 1.8 & & & & & & 0.6 & 2.1 & 0.5 \\
\hline Phe & 120.2 & 4.8 & 2.4 & 1.9 & .213 .7 & 0.9 & 2.5 & & 10.3 & 2.5 \\
\hline$(\text { Ttoal })^{4}$ & & loo:o & $120: 2.80$ & $100: 2.30$ & $405,11.85$ & $100: 2.90$ & $425: 10.20$ & 100: 240 & 411.7 & 100.0 \\
\hline Amino sugar & 0.8 & & 12.7 & & 94.5 & & 96.4 & & 91.3 & \\
\hline Total & 121.0 & & 132.7 & & 500.0 & & 521.4 & & 503.0 & \\
\hline
\end{tabular}

1) $\mu \mathrm{Mol}$ per $400 \mathrm{mg}$ rye-grass. 2) $\mu \mathrm{Mol}$ per $10 \mathrm{~g}$ sand. 3) $\mu \mathrm{Mol}$ per $10 \mathrm{~g}$ soil. 4) Total of amino acids. 5) Total of amino compounds. 


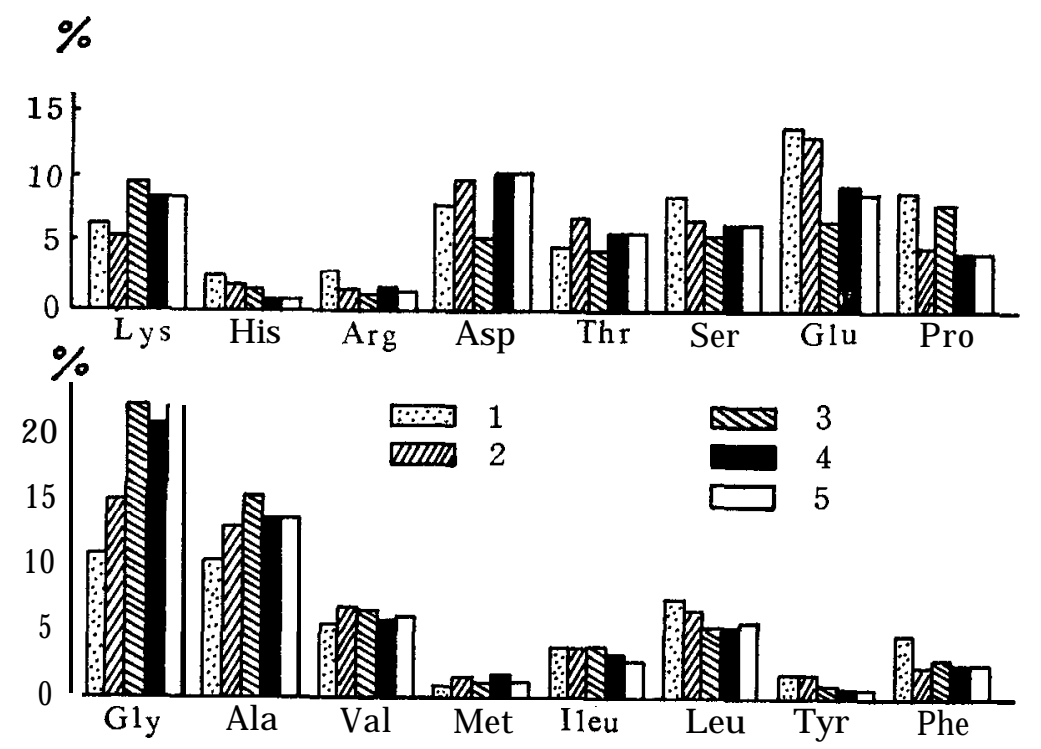

Fig. $3 \mathrm{Mol}$ per cents of the individual amino acids in the <Initial rye-grass $>$, the (Sand+rye-grass $>$, the <Soil+rye-grass $>$, the <Control soil $>$ and the $<$ Initial soil $>$.

1. (Initial rye-grass >, 2. <Sand+rye-grass>, 3. <Soil+rye-grass >, 4. <Control soil), 5. <Initial soil>.

the (Initial rye-grass) was $120.2 \mu \mathrm{Mol}$ of amino acid and $0.8 \mu \mathrm{Mol}$ of amino sugar per $400 \mathrm{mg}$ rye-grass and the (Sand+rye-grass), the (Soil+rye-grass), the (Control soil) and the (Initial soil) were $120.0 \mu \mathrm{Mol}, 405.5 \mu \mathrm{Mol}, 411.7 \mu \mathrm{Mol}$ and $425.0 \mu \mathrm{Mol}$ of amino acid and $12.7 \mu \mathrm{Mol}, 94.5 \mu \mathrm{Mol}, 91.3 \mu \mathrm{Mol}$ and $96.4 \mu \mathrm{Mol}$ of amino sugar per $10 \mathrm{~g}$ sand or soil, respectively. Concerning the amino compound analysis in this experiment, the experimental errors were about 10 percent. So, it seems that the amino compound contents of the (Soil+rye-grass), the (Control soil) and the (Initial soil) were almost equivalent, and their amino acid composition was almost similar as seen in Table 2.

As for the accumulation of amino compounds in the (Sand+rye-grass), each amino acid and amino sugar in the 〈Sand+rye-grass〉 are clearly originated from the added rye-grass on the whole, but not the same amino acid and amino sugar as contained in the added rye-grass initially. It might be considered that the amino acid and the amino sugar were newly synthesized by soil microorganisms through the decomposition of the added rye-grass, i. e., as to the contents of the amino acid and the amino sugar, the (Initial rye-grass\} is distinctly different in the (Sand+rye-grass). This suggests that when the rye-grass was added to sand, it was decomposed and the composition of amino compounds in the (Sand +rye-grass $>$ was exchanged by soil microorganisms through the synthesis of new amino acids and new amino sugars by them. Furthermore, as seen in Fig. 4 which showed the contents of amino sugar of each treatment including the (Initial rye-grass) and the (Initial soil), the amino sugar contents increased in the following order: the (Initial rye-grass) $<$ the $\langle$ Sand + rye-grass $\rangle \leqslant$ the (Soil+ rye-grass $)==$ the $($ Control soil)=the (Initial soil). This truely indicates that the 
amino sugar which were hardly contained in the added rye-grass was newly synthesized by soil microorganisms through the decomposition of the rye-grass and became accumulated in the soil because of its resistance to decomposition.

Next, we would like to consider about decomposition and synthesis of amino compounds in the (Soil+rye-grass). The content of amino compounds in it was $642.4(=521.4+121.0) \mu \mathrm{Mol}$ at the beginning and it became $500.0 \mu \mathrm{Mol}$ after B-month incubation. Within $500.0 \mu \mathrm{Mol},{ }^{11} \mathrm{C}$ originated from the added rye-grass was $13.5 \times 10^{4} \mathrm{cpm}$ as shown in Table 1 and it may be corresponded to about $143(=132.7 \times 13.5 / 12.5) \mu \mathrm{Mol}$, if we assume that ${ }^{11} \mathrm{C}$ activity in the amino compounds in the (Sand+rye-grass) is proportional to amino compound contents in it and this relationship is applied in the (Soilfrye-grass) correctly, too. And the amino compounds originated from the soil itself in the (Soilfrye-grass) may be about $357(=500-143) \mu \mathrm{Mol}$ and corresponded to $71.4(=357 / 500 \mathrm{x} 100)$ per cent of the amino compounds in the soil after 66 month incubation, i. e., it may be considered that about $28.6(=100-71.4)$ per cent of the native amino compounds might be exchanged by the newly synthesized amino compounds.

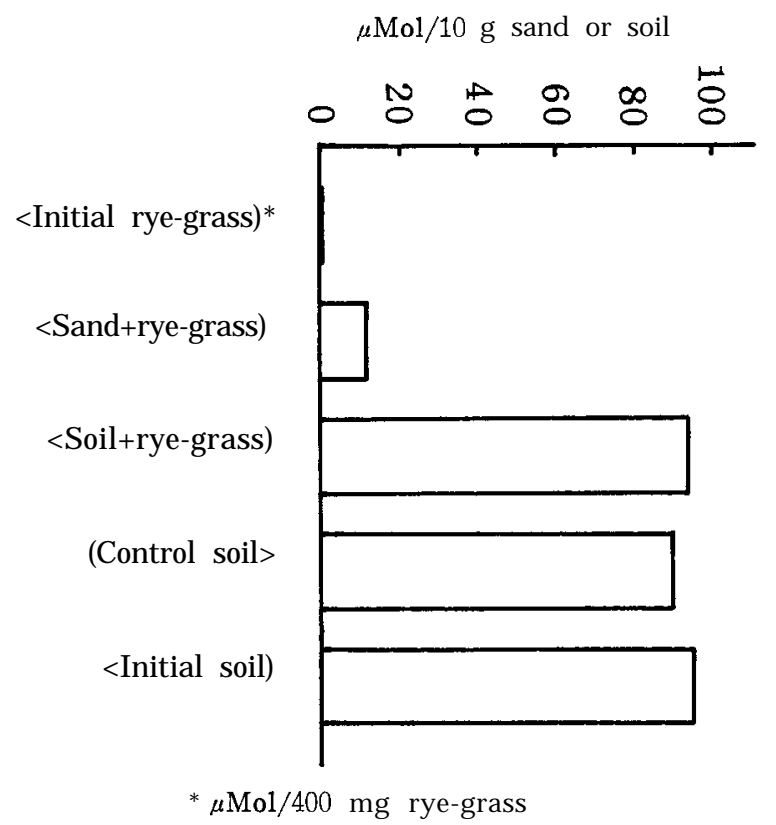

Fig. 4 Amino sugar $\mu \mathrm{Mol}$ in the $\varangle$ nitial rye-grass $\rangle$, the $\langle$ Sand + rye-grass $\rangle$, the $\langle$ Soil trye-grass), the <Control soil> and the (Initial soil>.

Further, as shown in Table 2, the amino compound contents of the (Soil+ rye-grass) and the (Control soil) were almost equivalent, so it is supposed that the amounts of the nitrogen almost equal to the nitrogen contained in the added rye-grass might be mineralized from the native nitrogen in the soil clue to the application of rye-grass. This may be explained by the results reported by Miyaguchi and Harada(1969), i. e., the phenomenon that the decomposition of the native soil organic matter is accelerated when bulky organic matters which 
contain chelating materials such as plant acids are added to soil.

In the second place, with regard to the percentage distribution of individual amino acids of the amino acid fraction in each treatment including the (Initial rye-grass) and the (Initial soil), as shown in Table 2 and Fig. 3, the (Initial rye-grass) showed that Glu was remarkably high in content, Gly, Ala, Pro, Ser and Asp were next, and Leu and Lys followed. However, in the 〈Sand+ryegrass), the (Soil+rye-grass), the (Control soil) and the (Initial soil), all of them indicated the following tendency in the contents of individual amino acids: Gly and Ala were in major amounts, Lys, Glu and Asp were next, and Ser, Thr and Leu followed. This suggests that the amino acid composition different from that of the added rye-grass was due to the exchange of amino acids through the amino acid metabolism of soil microorganisms.

In the (Sandfrye-grass), Glu which was the largest in the amino acid components of the added rye-grass decreased gradually for G-month incubation and Pro, Ser, Leu, Phe, Arg and His decreased as Glu. Reversely, Gly, Ala and Asp increased. Moreover, the amino acid composition of the (Sandfrye-grass) was almost similar to those of the (Control soil) and the (Initial soil). This indicates that it has a tendency to approach the amino acid composition in the (Initial soil) due to the application of rye-grass through the exchange of the amino acids.

In the (Soilfrye-grass), it is supposed that about 28.6 per cent of the amino compounds contained natively in the soil might be exchanged for the newly synthesized amino compounds as mentioned before, but its amino acid composition was almost similar to those of the (Control soil) and the (Initial soil) as shown in Table 2. That is, in the (Soil+rye-grass), Gly and Ala were distinctly high in content, Lys, Glu and Asp were next, and Ser, Thr and Leu followed.

As seen in Fig. 3, the Mol per cents of Glu, Pro, Ser, Leu, Phe, Arg, His and Tyr which were calculated as percentage of the total Mol of amino acid decreased in the following order as a tendency: the (Initial rye-grass $>>$ the $($ Sand+rye-grass $)>$ the (Soil+rye-grass) $>$ the (Control soil $\rangle \geqq$ the (Initial soil). In these amino acids, Glu decreased especially. Reversely, Gly, Ala, Lys and Asp increased and Gly increased remarkably in particular.

The amino acid composition of the (Initial soil) was not special and very similar to those of the paddy soils which were reported by many investigators so far. Therefore, it might be considered that the results obtained in this experiment suggest that when a carbonacious material like rye-grass is added to soil, it is decomposed and the composition of amino compounds in the soil is exchanged by soil microorganisms through the synthesis of new amino acids and amino sugars, and that the amino acid composition in the soil approaches what was contained in the soil natively for such a comparatively short period as 6 months, and newly synthesized amino sugars became accumulated in the soil because of its resistance to decomposition. Furthermore, considering about the amino acid composition of the organic nitrogen in the soil, in general Gly and Ala were remarkably high in content, Glu, Asp and Lys were next, and Val, Thr, Ser and Leu followed. And then, the amino sugars detected in the (Sand+rye-grass) and the (Soil+rye-grass) are well known to be major 
components of microbial cell walls.

From these results obtained in this experiment, we might consider that when a plant material such as rye-grass is added to soil, it is decomposed and the composition of amino compounds in the soil is exchanged by soil microorganisms through the synthesis of new amino acids and new amino sugars, and the amino acid composition in the soil approaches what was contained in the soil natively for such a comparatively short period as 6 months; in this case the amino sugars synthesized newly became accumulated in the soil because of its resistance to decomposition.

\section{CONCLUSIONS}

Experiments on a tendency of the contents of individual amino acids and amino sugars contained in the organic nitrogen in soil through the application of rye-grass labelled with ${ }^{14} \mathrm{C}$ uniformly were carried out and obtained the following results :

(1) In both the (Sand+rye-grass) and the (Soilfrye-grass), about 75 per cent of the added rye-grass ${ }^{14} \mathrm{C}$ were mineralized and volatilized as carbon dioxide for 6-month incubation.

(2) Part of ${ }^{11} \mathrm{C}$ added was incorporated into the amino acid fractions in the 〈Sand +rye-grass〉 and the (Soil+rye-grass) and the amounts of ${ }^{11} \mathrm{C}$ accumulation in each treatment were almost equivalent.

(3) Though the peaks of ${ }^{11} \mathrm{C}$-labelled amino sugar were not detected in the (Initial rye-grass), they were clearly detected in the (Sand +-rye-grass) and the (Soil+rye-grass). And the amino sugar contents increased in the following order: the (Initial rye-grass) <the <Sand+rye-grass > the (Soil+rye-grass)= the (Control soil $\rangle=$ the (Initial soil). This truely indicates that the amino sugar which were hardly contained in added rye-grass was newly synthesized by soil microorganisms through the decomposition of the rye-grass and became accumulated in the soil because of its resistance to decomposition.

(4) The (Initial rye-grass) showed that Glu was remarkably high in content, Gly, Ala, Pro, Ser and Asp were next, and Leu and Lys followed. However, in the (Sand+rye-grass), the <Soil+rye-grass), the <Control soil) and the <Initial soil), all of them indicated the following tendency in the contents of individual amino acids: Gly and Ala were in major amounts, Lys, Glu and Asp were next, and Ser, Thr and Leu followed. This suggests that the amino acid composition different from that of the added rye-grass was due to the exchange of amino acids through the amino acid metabolism of soil microorganisms.

(5) In view of each treatment including the (Initial rye-grass $>$ and the (Initial soil), the Mol per cents of Glu, Pro, Ser, Leu, Phe, Arg, His and Tyr which were calculated as percentage of the total Mol of amino acid decreased in the following order as a tendency: the (Initial rye-grass)> the 〈Sand+ryegrass: $>$ the <Soil+rye-grass)> the (Control soil)> the (Initial soil). In these amino acids, Glu decreased especially. Reversely, Gly, Ala, Lys and Asp increased and Gly increased remarkably in particular. 
(6) From the results of (3), (4) and (5), it might be considered that when a carbonaceous material like rye-grass is added to the paddy soil, it is decomposed and the composition of amino compounds in the soil is exchanged by soil microorganisms through the synthesis of new amino acids and new amino sugars and that the amino acid composition in the soil approaches what was contained in the soil natively for such a comparatively short period as 6 months. And Gly and Ala in the organic nitrogen of the soil are distinctly high in content, Glu, Asp and Lys are next, and Val, Thr, Ser and Leu follow. It is considered that the amino sugar compounds synthesized newly are accumulated in soil because of their resistance to decomposition.

\section{REFERENCES}

Bremnr, J. M., 1950. The amino acid composition of the protein material in soil. Biochem. J. $47: 538-542$.

Bremner, J. M. and Shaw, K., 1954. Studies on the estimation and decomposition of amino sugars in soil. J. Agr. Sci. 44: 152-159.

Davidson, D. I., Sowden, F. J. and Atkinson, H. J., $1951 . \quad$ Application of paper chromatography to identification and quantitative estimation of amino acids in soil organic matter fractions. Soil Sci. 71 : 347-352.

Elson, L. A. and Morgan, W. T. J., 1933. A colorimetric method for the determination of glucosamine and chondrosamine. Biochem. J.27: 1824-1828.

Hayashi, R. and Harada, T., 1969. Characterization of the organic nitrogen becoming decomposable through the effect of drying of a soil. Soil Sci. and Plant Nutr. 15: 226234.

Kosaka, J., Honda, C. and Iseki, A., 1959. A new rapid and accurate method for the determnation of carbon in soil. Soil and Plant Food. 5: 77-83.

Miyaguchi, M. and Harada, T., 1969. Green manure as a natural chelating agent. Part I. Agr. Bull. Saga Univ. 28: I-16.

Moore, S. and Stein, W. H., 1951. Chromatoraphy of amino acids on sulfonated polystyrene resins. J. Biol. Chem. 192: 663-681.

Sowden, F. J., 1955. Estimation of amino acids in soil hydrolysates by the Moore and Stein method. Soil Sci. 80: 181-188.

- 1959. Investigation on the amounts of hexosamines found in various soils and methods for their determination. Soil Sci. 88: 138-143.

_-, 1966. Nature of the amino acid compounds of soil. I. Soil Sci. 102: 202-207.

- , and Parker, D. I. 1353. Amino nitrogen of soils and of certain fractions isolated from them. Soil Sci. $76: 201-208$.

Stevenson, F. J., 1954. Ion exchange chromatography of the amino acids in soil hydrolysates. Soil Sci. Soc Amer. Proc. 18: 373-377.

-, $1956 \mathrm{a}$. Isolation and identification of some amino compounds in soil. Soil Sci. Soc. A mer. Proc. 20: 201-204.

-, $1956 \mathrm{~b}$. Effect of some long-time rotations on the amino acid composition of the soil. Soil Sci. Soc. Amer. Proc. 20: 204-208.

—, 1957a. Distribution of the forms of nitrogen in some soil profiles. Soil Sci. Soc. Amer. Proc. 21: 283-287.

- 1957 b. Investigation of amino polysaccharides in soil. I. Soil Sci. $83: 113-122$.

—, 1957 c. Investigation of amino polysaccharides in soil. II. Soil Sci. 84: 99-106.

Stevenson, F. J. and Braidss, 0. C., 1968. Variation in the relative distribution of amino sugars with depth in some soil profiles. Soil Sci. Soc. Amer. Proc. 32: 598-600. 
Wagner, G. H. and Mutatkar, V. K., 1968. Amino components of soil organic matter formed during humification of ${ }^{14} \mathrm{C}$ glucose. Soil Sci. Soc. Amer. Proc. Proc. 32 : 633-686.

Wang, T. S. C., Yang, T. K. and Cheng, S. Y., 1967. Amino acids in subtropical soil hydrolysates. Soil Sci. 103: 67-75.

Yamasita, T. and Akiya, T., 1966. Studies on nitrogenous composition of the humus in tobacco plant cultivated soils. Soil Sci. and Plant Nutr. 12: 31-35. 